
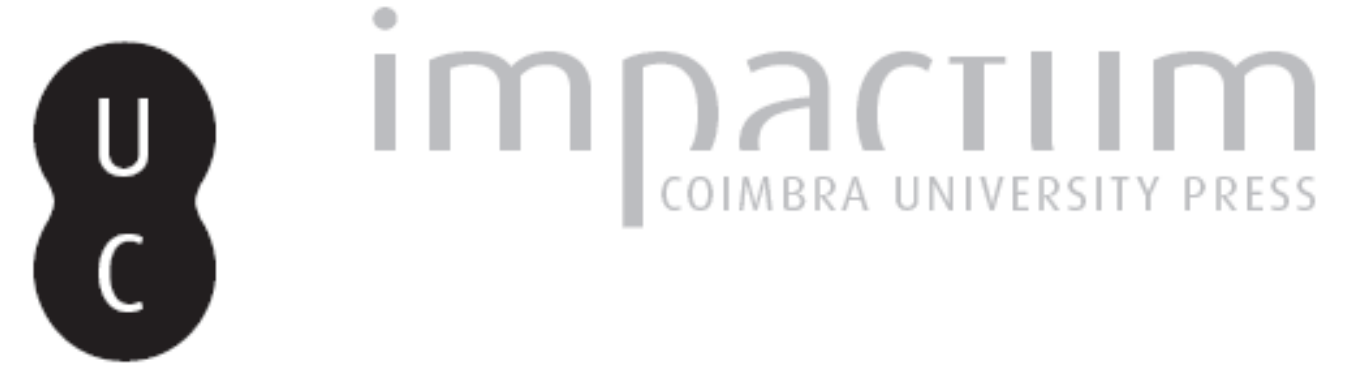

\title{
Avaliação do risco de incêndio em centros urbanos antigos parte l: aplicação do método de Arica ao centro histórico do Funchal
}

Autor(es): $\quad$ Figueira, Rui; Rodrigues, João Paulo C; Coelho, António Leça

Publicado por: Associação Portuguesa de Riscos, Prevenção e Segurança

URL

persistente:

URI:http://hdl.handle.net/10316.2/36051

DOI:

DOI:http://dx.doi.org/10.14195/1647-7723_18_8

Accessed : $\quad$ 26-Apr-2023 11:37:56

A navegação consulta e descarregamento dos títulos inseridos nas Bibliotecas Digitais UC Digitalis, UC Pombalina e UC Impactum, pressupõem a aceitação plena e sem reservas dos Termos e Condições de Uso destas Bibliotecas Digitais, disponíveis em https://digitalis.uc.pt/pt-pt/termos.

Conforme exposto nos referidos Termos e Condições de Uso, o descarregamento de títulos de acesso restrito requer uma licença válida de autorização devendo o utilizador aceder ao(s) documento(s) a partir de um endereço de IP da instituição detentora da supramencionada licença.

Ao utilizador é apenas permitido o descarregamento para uso pessoal, pelo que o emprego do(s) título(s) descarregado(s) para outro fim, designadamente comercial, carece de autorização do respetivo autor ou editor da obra.

Na medida em que todas as obras da UC Digitalis se encontram protegidas pelo Código do Direito de Autor e Direitos Conexos e demais legislação aplicável, toda a cópia, parcial ou total, deste documento, nos casos em que é legalmente admitida, deverá conter ou fazer-se acompanhar por este aviso.

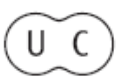




\section{territorium}

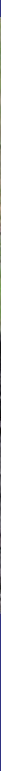

\section{Afirmar as Ciências Cindínicas}

Revista da Associação Portuguesa de Riscos, Prevenção e Segurança 

CENTRO HISTÓRICO DO FUNCHAL*

Serviço de Protecção Civil da Câmara Municipal do Funchal, ra.figueira@gmail.com

João Paulo C Rodrigues

Faculdade de Ciências e Tecnologia da Universidade de Coimbra, jpaulocr@dec.uc.pt

António Leça Coelho Laboratório Nacional de Engenharia Civil, alcoelho@lnec.pt

RESUMO

Avaliação do risco de incêndio em centros urbanos antigos parte I - Aplicação do método de ARICA ao centro histórico do Funchal - A diferente concepção e materiais usados nas construções antigas fazem com que estas apresentem um risco de incêndio agravado. Tendo como objectivo avaliar o risco de incêndio do centro histórico do Funchal aplicaramse os métodos de Gretener e ARICA a alguns edifícios característicos. A aplicação dos métodos permitiu não só verificar o risco de incêndio como detectar as diferenças entre os métodos.

Palavras-chave: risco, incêndio, método, centro, urbano, antigo.

\section{RESUMEN}

Evaluación del riesgo de incendio en centros urbanos antiguos parte I - Aplicación del método de ARICA en el centro histórico de Funchal - El diseño y los materiales utilizados en los edificios antiguos hace que estés presentan un riesgo de incendio agravado. Con el objetivo de evaluar el riesgo de incendio en el centro histórico de Funchal se aplicaron los métodos de Gretener y ARICA a algunos edificios característicos. La aplicación de los métodos no solo permitió comprobar el riesgo de incendio como detectar las diferencias entre los métodos.

Palabras-clave: riesgo, incendio, método, centro, urbano, antiguo.

\section{RESUMÈ}

Evaluation d'el risque de incendie de centres urbaines antique parte I-Application d'el méthode de ARICA al centre historique de Funchal - La conception et les matériaux utilisés dans les bâtiments anciens les amène à avoir une risque d'incendie aggravé. Dans le but d'évaluer le risque d'incendie du centre urbain antique de la ville de Funchal ont été appliquées des méthodes de Gretener et ARICA à certains bâtiments caractéristiques. L'application des méthodes a permis non seulement vérifier les risques d'incendie comme détecter les différences entre les méthodes.

Mot-clé: risque, le feu, la méthode, au centre-ville, en milieu urbain.

\section{ABSTRACT}

Fire Risk Assessment in Old Urban Areas part I - Application of the method of ARICA to the Historic Center of Funchal - The different design and materials used in old buildings aggravated their fire risk. This situation introduces problems of difficult solution to the old urban centers. With the aim of assessing the fire risk of the historic center of Funchal the methods of Gretener and ARICA were applied to some characteristic buildings. The application of the methods allowed not only to check the fire risk but also to detect the differences between the methods.

Keywords: risk, fire, method, center, urban, old.

\footnotetext{
* O texto deste artigo corresponde à comunicação apresentada ao II Congresso Internacional de Riscos e VI Encontro Nacional, tendo sido submetido para revisão em 08-06-2010, tendo sido aceite para publicação em 23-09-2010.

Este artigo é parte integrante da Revista Territorium, n. ${ }^{\circ}$ 18, 2011, ® RIscos, ISBN: 0872- 8941.
} 


\section{Introdução}

Os centros urbanos antigos das cidades Portuguesas podem ser definidos como locais constituídos por edificações que apresentam algum interesse histórico-cultural e também por edificações de menor interesse ou mesmo construções mais recentes. Os centros urbanos antigos podem ser caracterizados por ruas estreitas, sinuosas e / ou com grande declive, edificações contíguas, com aberturas muito próximas e coberturas à mesma altura, edificações essencialmente de cariz residencial com pequenos comércios familiares em geral no R/C, presença de edifícios devolutos e deteriorados, divisórias verticais e horizontais em materiais combustíveis, existência de caves e sótãos de acesso restrito ou dificultado, aberturas grandes em relação ao pé-direito, ligações de energia eléctrica e de gás antigas e sem manutenção, hidrantes e bocas-de-incêndio insuficientes, inexistentes ou com pouca pressão de água, ausência de sistemas de detecção de incêndio e alarme, parcela considerável da população residente idosa e destreinada para tomar as decisões acertadas em situação de sinistro, edificações abandonadas, estacionamento indiscriminado de carros particulares ao longo das vias, coexistência de edificações construídas em diferentes épocas históricas e falta de consciencialização da população quanto ao risco de armazenagem de materiais combustíveis em locais de pouco acesso e limpeza.

Nesta primeira parte do artigo, sobre o risco de incêndio em centros urbanos antigos, faz-se a aplicação dos métodos de Gretener e ARICA ao centro urbano antigo da cidade do Funchal. Para além da avaliação do risco de incêndio, fez-se a comparação entre os métodos detectando as suas potencialidades e debilidades.

\section{Métodos de Gretener e ARICA}

\section{Breve descrição do Método Gretener}

O objectivo deste método é a avaliação quantitativa do risco de incêndio. Este método pressupõe que sejam "observadas as regras gerais de segurança, tais como distâncias de segurança entre edifícios vizinhos e sobretudo as medidas de protecção das pessoas como saídas de evacuação, iluminação de segurança, etc., bem como as prescrições correspondentes às instalações técnicas. Tais medidas não podem ser substituídas por quaisquer outras." (Lemos e Neves, 1987).

Este método, face aos parâmetros considerados, faz a distinção entre perigos potenciais e medidas de protecção, sendo que os factores que constituem o primeiro favorecem, e do segundo dificultam o desenvolvimento dos incêndios.
A fórmula de base deste método é dada pela seguinte equação:

$$
B=\frac{P}{M}
$$

onde:

$B$ - factor de exposição ao perigo de incêndio

$P$ - factores de perigo potencial

M - factores de protecção

Com base em critérios adoptados por este método, a fórmula anterior passa a figurar o seguinte aspecto:

$$
B=\frac{\text { q.c.r.k. i.e.g. }}{\text { N.S.F. }}=\frac{P}{\text { N.S.F. }}
$$

Tendo os factores o significado indicado no QUADRo I:

QUADRo I - significado dos factores do perigo potencial e de protecção

\begin{tabular}{|c|c|c|}
\hline Factor & Designação dos perigos & Atribuição \\
\hline $\mathrm{q}$ & Carga de incêndio mobiliária & Perigos \\
$\mathrm{c}$ & Combustibilidade & inerentes \\
$\mathrm{r}$ & Formação de fumo & ao \\
$\mathrm{k}$ & Perigo de corrosão/toxicidade & conteúdo \\
\hline $\mathrm{I}$ & Carga de incêndio imobiliária & Perigos \\
$\mathrm{E}$ & Nível do andar ou altura do local & inerentes \\
$\mathrm{g}$ & Amplidão dos compartimentos & ao \\
& de incêndio e sua relação & edifício \\
& comprimento/largura & \\
\hline \multicolumn{2}{|c}{} \\
\hline
\end{tabular}

0 risco de incêndio efectivo $R$ resulta do valor de exposição ao perigo $B$ multiplicado pelo factor de perigo de activação $A$, ilustrado da seguinte forma:

$$
R=B \cdot A=\frac{P}{N \cdot S \cdot F \cdot} \cdot A
$$

Para definir o risco de incêndio admissível o método propõe partir de um "risco normal" e introduzir um factor de correcção tendo em conta o perigo para as pessoas.

$$
\mathrm{R}_{\mathrm{u}}=\mathrm{R}_{\mathrm{n}} \cdot \mathrm{P}_{\mathrm{HE}}
$$

onde:

$R_{u}$ - risco de incêndio admissível

$R_{n}=1,3$ - risco de incêndio normal

$P_{H E}$ - factor de correcção do risco normal em função do número de pessoas e do nível do andar

em que:

$P_{H E}<1$ para perigo de pessoas acrescido

$P_{H E}=1$ para perigo de pessoas normal

$P_{H E}>1$ para perigo de pessoas reduzido

A verificação da segurança contra incêndio é feita comparando-se o risco de incêndio efectivo $R$ com o risco de incêndio admissível $R_{u}$, sendo suficiente quando o primeiro não é superior ao segundo, ou seja: 


$$
R_{u} \geq R
$$

Esta condição exprime-se através do conceito de "segurança contra incêndio $\gamma$ ":

$$
Y=\frac{R_{u} \geq 1}{R}
$$

Se $\gamma<1$, significa que o edifício ou o compartimento de incêndio está insuficientemente protegido contra incêndio.

\section{Breve descrição do Método de ARICA}

Sendo o método ARICA, comparativamente ao Gretener, muito menos conhecido das pessoas em geral, efectua-se uma breve descrição do mesmo (Fernandes, 2006).

0 método assenta no princípio que os edifícios situados nos centros urbanos antigos não podem possuir um grau de risco superior ao dos edifícios recentes. Esse princípio assenta nos seguintes fundamentos:

- Por viverem num centro urbano antigo, as pessoas não podem ser sujeitas a riscos superiores, do ponto de vista da segurança ao incêndio; e

- Os centros urbanos antigos representam para o imaginário colectivo uma importância que excede, muitas vezes, a dos edifícios novos, pelo que devem ser criadas condições de os preservar.

Assumindo estes princípios, as exigências consideradas para os novos edifícios serviram para definir o limiar de risco admissível para os edifícios existentes (Factor de Risco de Incêndio - FRI). Este limiar de risco é comparado com um Factor de Risco de Referencia (FRR), o qual é determinado a partir de três factores globais de risco e de um factor global de eficácia.

Os factores globais de risco e o factor global de eficácia são os seguintes:

- Factor Global de Risco associado ao início de incêndio $\left(\mathrm{FG}_{\|}\right)$;

- Factor Global de Risco associado ao desenvolvimento e propagação do incêndio no edifício $\left(\mathrm{FG}_{\mathrm{DPI}}\right)$;

- Factor Global de Risco associado à evacuação do edifício $\left(\mathrm{FG}_{\mathrm{EE}}\right)$;

- Factor Global de Eficácia associado ao combate ao incêndio $\left(F G_{C I}\right)$.

Por sua vez, cada factor global é constituído por diversos factores parciais. No caso do $\mathrm{FG}_{\|}$, é constituído pelos seguintes factores parciais:

- Estado de conservação da construção $\left(\mathrm{F}_{\mathrm{EC}}\right)$;

- Instalações eléctricas $\left(\mathrm{F}_{\mathrm{IEL}}\right)$;
Instalações de gás $\left(F_{1 G}\right)$;

- Natureza das cargas de incêndio mobiliárias $\left(\mathrm{F}_{\mathrm{NCI}}\right)$.

Do $F_{\mathrm{DPI}}$ fazem parte os seguintes factores parciais:

- Conteúdo do edifício - Cargas de incêndio mobiliárias $\left(\mathrm{F}_{\mathrm{CI}}\right)$;

- Compartimentação corta-fogo $\left(\mathrm{F}_{\mathrm{CCF}}\right)$;

- Detecção, alarme e alerta de incêndio $\left(F_{D I}\right)$;

- Equipas de segurança $\left(F_{E S}\right)$;

- Propagação pelo exterior - Afastamento entre vãos sobrepostos $\left(\mathrm{F}_{\mathrm{AV}}\right)$.

Quanto ao terceiro factor global, o $\mathrm{FG}_{\mathrm{EE}}$, é constituído pelos seguintes parciais:

- Largura dos diversos elementos dos caminhos de evacuação $\left(F_{L}\right)$;

- Distância a percorrer nas vias de evacuação $\left(\mathrm{F}_{\mathrm{DVE}}\right)$;

- Número de saída dos locais $\left(\mathrm{F}_{\mathrm{NLL}}\right)$;

- Inclinação das vias verticais de evacuação $\left(\mathrm{F}_{\mathrm{IVE}}\right)$;

- Protecção das vias de evacuação $\left(\mathrm{F}_{\mathrm{PV}}\right)$;

- Controlo de fumo das vias de evacuação $\left(F_{C F}\right)$;

- Sinalização e iluminação de emergência $\left(F_{S 1}\right)$;

- Detecção, alarme e alerta de incêndio $\left(F_{D I}\right)$;

- Equipas de segurança $\left(\mathrm{F}_{\mathrm{ES}}\right)$;

- Realização de exercícios de evacuação $\left(\mathrm{F}_{\mathrm{EE}}\right)$.

Quando ao Factor Global de eficácia, o $\mathrm{FG}_{\mathrm{Cl}}$ é constituído pelos seguintes factores parciais:

- Acessibilidade ao edifício $\left(\mathrm{F}_{\mathrm{AE}}\right)$;

- Hidrantes exteriores $\left(\mathrm{F}_{\mathrm{HE}}\right)$;

- Fiabilidade da rede de alimentação de água $\left(\mathrm{F}_{\mathrm{F}}\right)$;

- Extintores $\left(\mathrm{F}_{\mathrm{EXT}}\right)$;

- Redes de incêndio armadas $\left(\mathrm{F}_{\mathrm{RIA}}\right)$;

- Colunas secas ou húmidas $\left(\mathrm{F}_{\mathrm{CS} / \mathrm{H}}\right)$;

- Sistemas automáticos de extinção $\left(\mathrm{F}_{\mathrm{SAE}}\right)$;

Destes quatro factores globais resulta o FRI, através da seguinte expressão:

$F R I=\left(1,2 \times F G_{\|}\right) \times\left(1,1 \times F G_{D P I}\right) \times F G_{E E} \times F G_{C I}$

Comparando-se o FRI com o FRR obtém-se o risco de incêndio:

Risco de Incêndio $=\frac{\text { FRI }}{\text { FRR }}$

O FRR é tabelado, tomando o valor 1,3 para os edifícios correntes e 1,95 para os edifícios industriais, armazéns, bibliotecas e arquivos. 
Se o risco de incêndio for inferior ou igual a 1 significa que o edifício não apresenta problemas assinaláveis em termos da segurança ao incêndio.

Se o risco for superior a 1, terão que ser adoptadas medidas para melhorar a segurança ao incêndio no edifício.

\section{Potencialidades e diferenças dos Métodos de Gretener e de ARICA}

0 método ARICA é mais abrangente que o de Gretener embora este último seja de mais fácil aplicação. 0 método de Gretener supõe à partida que o edifício a ser analisado garante as regras gerais de segurança, tais como as medidas de protecção das pessoas, as saídas de evacuação, a iluminação de emergência ou até mesmo que são verificadas as prescrições das instalações técnicas.

Sabendo-se de antemão que a realidade dos centros urbanos antigos, quanto ao risco de incêndio associado, resulta da não verificação das medidas de segurança contra incêndios, a aplicação do método de Gretener impõe que algumas medidas sejam verificadas ou, em último caso adaptadas, embora a realidade existente não o permita, pelos mais variados motivos. 0 método de Gretener pode ser considerado como mais permissivo na escolha dos parâmetros a considerar para as diferentes situações do que o ARICA.

O método ARICA tende a abranger a totalidade das regras gerais de segurança. Por esse facto torna mais complexa a sua aplicação, obrigando a conhecer uma realidade profunda das condições do edifício. Desde as condições de manutenção geral do edificado até às medidas de auto-protecção que este método pretende verificar.

\section{Casos de Estudo}

O Decreto Legislativo Regional $n^{\circ} 21 / 86 / M$, de 2 de Outubro, classificou a zona antiga da cidade do Funchal como conjunto arquitectónico de valor regional e impôs os seus limites. Os edifícios analisados situam-se no Núcleo Histórico da Sé (FIGUeIra, 2008).

Os quatro edifícios analisados, e que se identificam de imediato, podem ser considerados como típicos dos núcleos históricos do Funchal:

- Loja de pronto-a-vestir à Rua da Queimada de Cima;

- Tipografia à Rua da Queimada de Cima;

- Ourivesaria à Rua da Queimada de Cima;

- Edifício de escritórios à Rua do Bispo.

A escolha destes edifícios recaiu no facto de serem representativos da tipologia, volumetria e utilizações- tipo dos edifícios do centro histórico do Funchal. Com esta escolha, será mais fácil iniciar-se uma caracterização do risco de incêndio de forma mais genérica do restante edificado com base na sua ocupação, volumetria e utilização.

O centro histórico do Funchal é conhecido como uma zona comercial e de serviços com poucos edifícios de habitação, com uma grande ocupação diurna e quase desertificado à noite. No quarteirão em análise não é conhecida a habitação de pessoas de forma permanente.

As lojas, escritórios, restaurantes e bares, existentes neste "centro comercial e de serviços" da cidade, são predominantemente de pequenas dimensões. 0 quarteirão da zona em análise possui acesso automóvel condicionado, com a possibilidade de circulação de viaturas ao início da manhã para cargas e descargas. Os bombeiros possuem chaves dos pontos de acesso condicionados pela existência de pinos amovíveis.

- Loja de pronto-a-vestir

Esta loja trata-se de um estabelecimento comercial típico no centro do Funchal, de reduzidas dimensões, ocupando o piso do rés-do-chão de um edifício de 3 pisos, estando os restantes pisos devolutos ou desocupados (fig. 1).

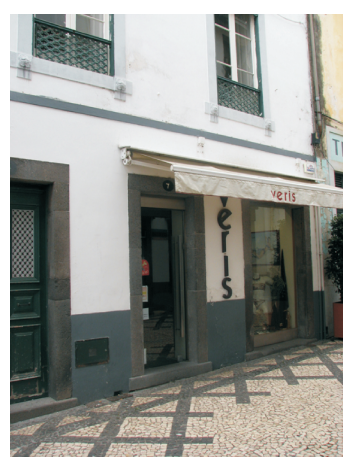

Fig. 1 - Loja de pronto-a-vestir.

Este estabelecimento está inserido num edifício que se caracteriza por uma construção com paredes em alvenaria de pedra, as quais também servem de separação para os edificios vizinhos, com os pavimentos de separação entre os diversos pisos em soalho tradicional de madeira assente em vigas de madeira. Possui um tecto falso em placas de gesso cartonado pintado, em toda a sua área. As paredes entre os edifícios vizinhos são rebocadas e pintadas enquanto as paredes divisórias são em alvenaria de betão, rebocadas e pintadas. As caixilharias de janelas e portas são em alumínio. A cobertura é revestida a telha cerâmica assente em estrutura de madeira.

As medidas activas existentes caracterizam-se por um sistema automático de detecção de incêndio, sem linha telefónica dedicada, extintores portáteis e iluminação e sinalização de emergência. 


\section{- Tipografia}

Trata-se de um estabelecimento antigo, com paredes exteriores em alvenaria de pedra, as quais são interiormente rebocadas e pintadas e servem de separação para os edificios vizinhos. 0 edifício não possui quaisquer paredes divisórias interiores (figs. 2 e 3). Todos os pavimentos são em madeira e as portas e caixilharia das janelas da fachada são em alumínio. A cobertura é revestida a telha cerâmica apoiada em estrutura de madeira. A escada que liga os três pisos é de estrutura metálica de reduzidas dimensões.

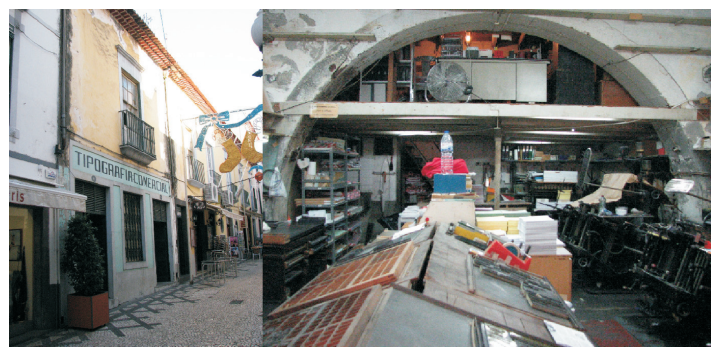

Fig. 2 - Alçado (esquerda) e zona de laboração no Piso 0 (direita) da Tipografia Comercial.

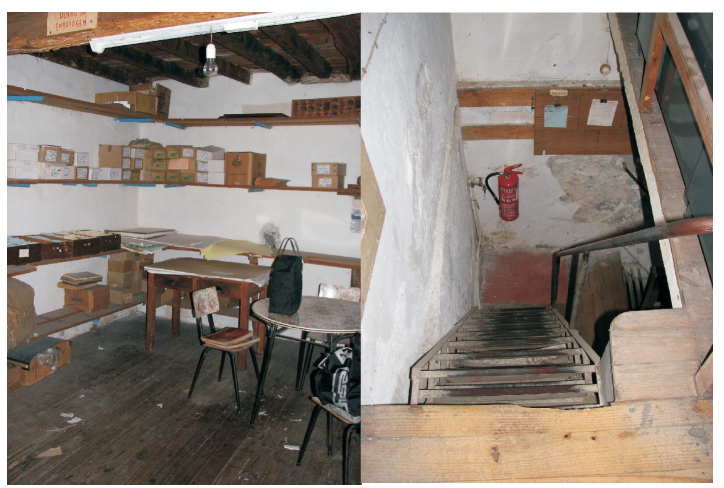

Fig. 3 - Piso 2, onde se situam os arrumos (esquerda) e o seu acesso (direita).

Este edifício é representativo de algumas pequenas indústrias que existem há décadas no núcleo histórico. Quanto ao tipo de carga de incêndio foi possível definir três zonas distintas, definidas como armazém de imprensa, oficina tipográfica de imprensa e zona de embalagem.

Este estabelecimento possui um sistema automático de detecção de incêndio, sem linha telefónica dedicada, extintores portáteis e iluminação e sinalização de emergência.

\section{- Ourivesaria}

Este estabelecimento, uma ourivesaria de pequenas dimensões, ocupa os pisos 1, 2 e 3 de um edifício, que apresenta uma ocupação distinta no piso 0 (fig. 4). 0 acesso é feito através de escada de tiro. Os pavimentos do edifício são em soalho tradicional apoiados em vigas de madeira. As paredes de separação com os edificios vizinhos são em alvenaria de pedra interiormente rebocadas e pintadas. 0 estabelecimento comercial do $\mathrm{R} / \mathrm{C}$ possui um tecto falso em placas de gesso cartonado pintado.

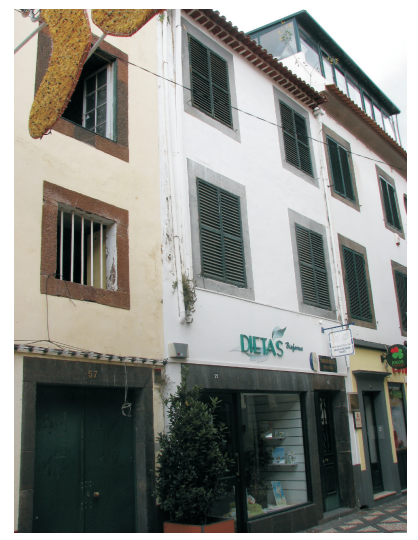

Fig. 4 - Vista do alçado frontal da ourivesaria.

Os pavimentos de separação da ourivesaria são em madeira, sem qualquer tipo de tecto falso. As paredes interiores divisórias são em tabique pintadas enquanto a estrutura do telhado é em madeira. 0 revestimento do telhado é em telha cerâmica.

A loja não possuía quaisquer medidas normais ou especiais, tais como sistema de detecção, extintores ou outros.

\section{- Edifício de escritórios}

Este edifício de escritórios é classificado de interesse público e constitui um dos ex-líbris do Funchal (fig. 5). O edifício é composto por dois corpos, um inferior de três pisos com grande desenvolvimento em planta, e um superior de reduzidas dimensões em planta com três pisos. Este edifício é um dos mais altos do núcleo histórico da Sé.

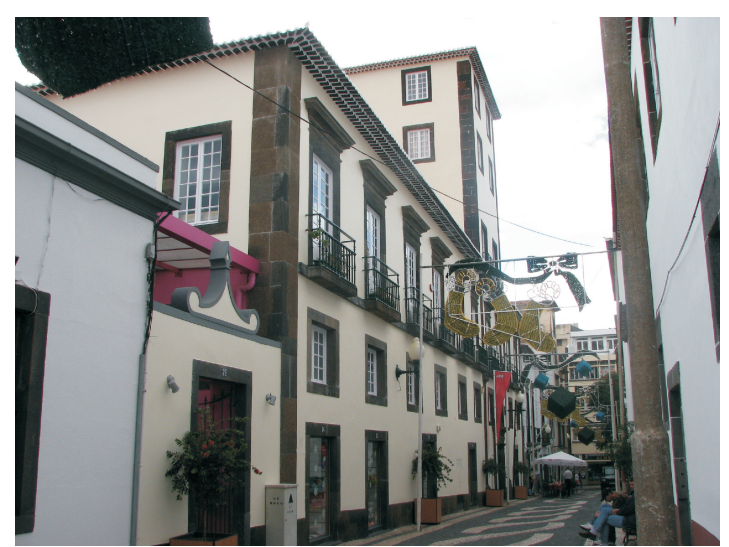

Fig. 5 - Vista exterior do edifício de escritórios (Palácio dos Ornelas). 
0 piso 0 é independente dos restantes pisos. A este nível existem duas lojas, não consideradas neste estudo.

Em 1992, o edifício foi totalmente remodelado, com a demolição da cobertura e pavimentos, ficando somente as paredes exteriores. As obras realizadas promoveram a construção de lajes e escadas em betão armado, amarradas às paredes exteriores em alvenaria de pedra. Os pavimentos são revestidos a madeira ou mosaico cerâmico.

Todos os tectos das zonas comuns e escritórios são rebocados e pintados.

As paredes divisórias interiores são em alvenaria de betão, rebocadas e pintadas.

A cobertura encontra-se revestida a telha cerâmica, assente sobre sub-telha em fibrocimento, apoiada numa estrutura em perfis de aço.

As caixilharias exteriores, portas e janelas, são em madeira pintada, incluindo os aros e as forras.

Os escritórios em todos os pisos são de área inferior a $100 \mathrm{~m}^{2}$, separados por paredes de alvenaria de betão. A escada interior é não enclausurada encerrando no seu interior o elevador. Este edifício não possui quaisquer medidas normais ou especiais de segurança contra incêndio importantes.

\section{Parâmetros considerados em cada método}

\section{Método de Gretener}

\section{Parâmetros comuns aos vários casos de estudo}

Neste ponto são apresentados os valores dos parâmetros comuns aos vários casos sendo os valores dos parâmetros específicos apresentados nos pontos seguintes.

Nas medidas normais, o factor $\mathrm{n}_{3}$, referente à fiabilidade do sistema de abastecimento de água, foi considerado igual a 0,9 . A rede de distribuição pública de água que abastece os três núcleos históricos foi totalmente remodelada nos últimos 2 anos, sendo as condutas novas em ferro fundido. 0 abastecimento desta rede é feito por gravidade, através de um reservatório de $8000 \mathrm{~m}^{3}$. Segundo fonte do Departamento de Água e Saneamento Básico da Câmara Municipal do Funchal (CMF), são garantidas pressões na ordem dos 7 Bar $(0,7 \mathrm{kPa})$ na zona de análise e condições de caudal elevadas. Segundo a mesma fonte, o caudal extraído dos marcos de incêndio é condicionado pelas suas características e não pela rede de distribuição pública. O reservatório não possui qualquer reserva exclusiva para incêndios.

Além desta rede, existe uma outra denominada "rede de alta pressão", com melhores características a nível de pressão e caudal, que segundo a mesma fonte, apresenta uma pressão de 10 Bar.

Face ao facto da fiabilidade não poder ser comprovada com acesso a valores estatísticos, o valor assumido para o factor $n_{3}$ foi 0,9 .

Para a determinação do valor do factor $s_{3}$ considerouse a existência de um corpo de bombeiros da categoria 7, definindo-se o seu valor como 1,60. O Funchal possui duas corporações distintas e relativamente próximas, os Bombeiros Municipais do Funchal (BMF) e os Bombeiros Voluntários Madeirenses (BVM). Os BMF são uma corporação que conta com 124 elementos, todos profissionais, e os BVM uma corporação mista, com um número semelhante de bombeiros, dos quais sensivelmente $50 \%$ são profissionais. Os meios existentes nos BMF e BVM foram considerandos suficientes para considerá-los na categoria 7.

Face à proximidade das corporações, o tempo estimado de chegada à zona é inferior a 15 minutos, adoptando-se assim o factor $\mathrm{s}_{4}$ com um valor de 1,0 .

A distância dos vários edifícios em análise às bocas-deincêndio ou marcos de incêndio mais próximos é variável mas nunca superior a $100 \mathrm{~m}$, sendo adoptado o valor 0,95 ou 1,00 para o factor $n_{4}$.

Em todos os casos verificou-se a inexistência de formação do pessoal, sendo adoptado o valor 0,80 no factor $n_{5}$.

Sempre que na descrição dos cálculos referentes aos vários edifícios se faz referência a medidas normais, especiais e de construção, elas correspondem às consideradas pelo método de Gretener.

\section{Parâmetros específicos dos vários casos de estudo}

Os Quadros II a xIv apresentam os valores dos factores dos perigos potenciais e os restantes factores das medidas de protecção ainda não definidos para cada um dos edifícios estudados.

- Loja de pronto-a-vestir

QUADRO II - factores dos perigos potenciais da loja de pronto-a-vestir

\begin{tabular}{|l|l|l|}
\hline \multirow{4}{*}{ P e r i g o s } & Carga de incêndio Mobiliária ( q ) & 1,30 \\
\cline { 2 - 3 } potenciais & Combustibilidade ( c ) & 1,20 \\
\cline { 2 - 3 } & Perigo de fumo ( r ) & 1,00 \\
\cline { 2 - 3 } & Perigo de corrosão ( k ) & 1,00 \\
\cline { 2 - 3 } & Carga de incêndio imobiliária ( i ) & 1,10 \\
\cline { 2 - 3 } & Nível do piso ( e ) & 1,00 \\
\cline { 2 - 3 } & Amplidão de superfície ( g ) & 0,40 \\
\hline
\end{tabular}


QUADRO III - resumo dos restantes factores da loja de pronto-a-vestir.

\begin{tabular}{|c|c|c|c|c|}
\hline & & & \multicolumn{2}{|c|}{ Variantes } \\
\hline & & & 1 & 2 \\
\hline \multirow{11}{*}{$\begin{array}{l}\text { Medidas de } \\
\text { Protecção }\end{array}$} & \multirow{3}{*}{$\begin{array}{l}\text { Medidas } \\
\text { Normais }\end{array}$} & Extintores Portáteis $\left(n_{1}\right)$ & 1,00 & 0,90 \\
\hline & & Bocas-de-incêndio $\left(\mathrm{n}_{2}\right)$ & 0,80 & $\cdots$ \\
\hline & & Formação funcionários $\left(\mathrm{n}_{5}\right)$ & 0,80 & $\cdots$ \\
\hline & \multirow{4}{*}{$\begin{array}{l}\text { Me didas } \\
\text { especiais }\end{array}$} & Detecção de incêndio $\left(s_{1}\right)$ & 1,45 & 1,00 \\
\hline & & Transmissão de alarme $\left(\mathrm{s}_{2}\right)$ & 1,00 & $\cdots$ \\
\hline & & Extinção automática $\left(\mathrm{S}_{5}\right)$ & 1,00 & $\cdots$ \\
\hline & & Desenfumagem $\left(\mathrm{s}_{6}\right)$ & 1,00 & $\cdots$ \\
\hline & \multirow{4}{*}{$\begin{array}{l}\text { Medidas de } \\
\text { construção }\end{array}$} & Resistência da estrutura $\left(\mathrm{f}_{1}\right)$ & 1,20 & 1,00 \\
\hline & & Resistência da fachada $\left(\mathrm{f}_{2}\right)$ & 1,10 & 1,00 \\
\hline & & Separação entre pisos $\left(f_{3}\right)$ & 1,15 & 1,00 \\
\hline & & Células corta-fogo $\left(\mathrm{f}_{4}\right)$ & 1,20 & 1,00 \\
\hline
\end{tabular}

\section{- Tipografia}

QUADRO IV - factores dos perigos potenciais da tipografia.

\begin{tabular}{|l|l|l|}
\hline & Carga de incêndio Mobiliária (q) & 1,90 \\
\cline { 2 - 3 } & Combustibilidade (c) & 1,60 \\
\cline { 2 - 3 } Perigos potenciais & Perigo de fumo (r) & 1,20 \\
\cline { 2 - 3 } & Perigo de corrosão (k) & 1,00 \\
\cline { 2 - 3 } & Carga de incêndio imobiliária (i) & 1,20 \\
\cline { 2 - 3 } & Nível do piso (e) & 1,30 \\
\cline { 2 - 3 } & Amplidão de superfície (g) & 0,40 \\
\hline
\end{tabular}

QUADRO V - resumo dos restantes factores da tipografia.

\begin{tabular}{|c|c|c|c|c|}
\hline & & & \multicolumn{2}{|c|}{ Variantes } \\
\hline & & & 1 & 2 \\
\hline \multirow{11}{*}{$\begin{array}{l}\text { Medidas de } \\
\text { Protecção }\end{array}$} & \multirow{3}{*}{$\begin{array}{l}\text { Medidas } \\
\text { Normais }\end{array}$} & Extintores Portáteis $\left(\mathrm{n}_{1}\right)$ & 1,00 & 0,90 \\
\hline & & Bocas-de-incêndio $\left(\mathrm{n}_{2}\right)$ & 0,80 & ......... \\
\hline & & Formação dos funcionários $\left(\mathrm{n}_{5}\right)$ & 0,80 & (n........ \\
\hline & \multirow{4}{*}{$\begin{array}{l}\text { Medidas } \\
\text { especiais }\end{array}$} & Detecção de incêndio $\left(s_{1}\right)$ & 1,45 & 1,00 \\
\hline & & Transmissão de alarme $\left(\mathrm{s}_{2}\right)$ & 1,00 & (n........ \\
\hline & & Extinção automática $\left(\mathrm{s}_{5}\right)$ & 1,00 & -........ \\
\hline & & Desenfumagem $\left(\mathrm{s}_{6}\right)$ & 1,00 & (......... \\
\hline & \multirow{4}{*}{$\begin{array}{l}\text { Medidas de } \\
\text { construção }\end{array}$} & Resistência da estrutura $\left(\mathrm{f}_{1}\right)$ & 1,20 & 1,00 \\
\hline & & Resistência da fachada $\left(\mathrm{f}_{2}\right)$ & 1,10 & 1,00 \\
\hline & & Separação entre pisos $\left(f_{3}\right)$ & 1,15 & 1,00 \\
\hline & & Células corta-fogo $\left(f_{4}\right)$ & 1,20 & 1,00 \\
\hline
\end{tabular}

\section{- Ourivesaria}

QUADRO VI - factores dos perigos potenciais da ourivesaria.

\begin{tabular}{|l|l|l|}
\hline \multirow{4}{*}{$\begin{array}{l}\text { P e r i g o s } \\
\text { potenciais }\end{array}$} & Carga de incêndio Mobiliária ( q ) & 1,40 \\
\cline { 2 - 3 } & Combustibilidade ( c ) & 1,20 \\
\cline { 2 - 3 } & Perigo de fumo ( r ) & 1,00 \\
\cline { 2 - 3 } & Perigo de corrosão ( k ) & 1,00 \\
\cline { 2 - 3 } & Carga de incêndio imobiliária ( i ) & 1,20 \\
\cline { 2 - 3 } & Nível do piso ( e ) & 1,65 \\
\cline { 2 - 3 } & Amplidão de superfície ( g ) & 0,40 \\
\hline
\end{tabular}

QUADRO VII - resumo dos restantes factores da ourivesaria.

\begin{tabular}{|c|c|c|c|c|}
\hline & & & \multicolumn{2}{|c|}{ Variantes } \\
\hline & & & 1 & 2 \\
\hline \multirow{11}{*}{$\begin{array}{l}\text { Medidas de } \\
\text { Protecção }\end{array}$} & \multirow{3}{*}{$\begin{array}{l}\text { Me di d a s } \\
\text { Normais }\end{array}$} & Extintores Portáteis $\left(\mathrm{n}_{1}\right)$ & 0,90 & 1,00 \\
\hline & & Bocas-de-incêndio $\left(\mathrm{n}_{2}\right)$ & 0,80 & $\cdots+\cdots \cdot$ \\
\hline & & $\begin{array}{l}\text { Formação dos funcionários } \\
\left(\mathrm{n}_{5}\right)\end{array}$ & 0,80 & 1,00 \\
\hline & \multirow{4}{*}{$\begin{array}{l}\text { Me d i d a s } \\
\text { especiais }\end{array}$} & Detecção de incêndio $\left(\mathrm{s}_{1}\right)$ & 1,00 & 1,45 \\
\hline & & Transmissão de alarme $\left(\mathrm{s}_{2}\right)$ & 1,00 & 1,20 \\
\hline & & Extinção automática $\left(\mathrm{s}_{5}\right)$ & 1,00 & -........ \\
\hline & & Desenfumagem $\left(\mathrm{s}_{6}\right)$ & 1,00 & -........ \\
\hline & \multirow{4}{*}{$\begin{array}{l}\text { Medidas de } \\
\text { construçã̃o }\end{array}$} & Resistência da estrutura $\left(f_{1}\right)$ & 1,00 & $\cdots+\cdots \cdot$ \\
\hline & & Resistência da fachada $\left(\mathrm{f}_{2}\right)$ & 1,10 & -........ \\
\hline & & Separação entre pisos $\left(f_{3}\right)$ & 1,00 & (n....... \\
\hline & & Células corta-fogo $\left(f_{4}\right)$ & 1,00 & …..... \\
\hline
\end{tabular}

\section{- Edifício de escritórios}

QUADRO VIII - factores dos perigos potenciais do edifício de escritórios.

\begin{tabular}{|l|l|l|}
\hline \multirow{4}{*}{ Perigos potenciais } & Carga de incêndio Mobiliária (q) & 1,60 \\
\cline { 2 - 3 } & Combustibilidade (c) & 1,20 \\
\cline { 2 - 3 } & Perigo de fumo (r) & 1,00 \\
\cline { 2 - 3 } & Perigo de corrosão (k) & 1,00 \\
\cline { 2 - 3 } & Carga de incêndio imobiliária (i) & 1,10 \\
\cline { 2 - 3 } & Nível do piso (e) & 1,95 \\
\cline { 2 - 3 } & Amplidão de superfície (g) & 0,40 \\
\hline
\end{tabular}

QUADRO IX - resumo dos restantes factores do edifício de escritórios.

\begin{tabular}{|c|c|c|c|c|}
\hline & & & \multicolumn{2}{|c|}{ Variantes } \\
\hline & & & 1 & 2 \\
\hline \multirow{11}{*}{$\begin{array}{l}\text { Medidas } \\
\text { de Protec- } \\
\text { ção }\end{array}$} & \multirow{3}{*}{$\begin{array}{l}\text { Medidas } \\
\text { Normais }\end{array}$} & Extintores Portáteis $\left(n_{1}\right)$ & 0,90 & 1,00 \\
\hline & & Bocas-de-incêndio $\left(\mathrm{n}_{2}\right)$ & 0,80 & 1,00 \\
\hline & & $\begin{array}{l}\text { Formação dos funcionários } \\
\left(\mathrm{n}_{5}\right)\end{array}$ & 0,80 & 1,00 \\
\hline & \multirow{4}{*}{$\begin{array}{l}\text { Medidas } \\
\text { especiais }\end{array}$} & Detecção de incêndio $\left(s_{1}\right)$ & 1,00 & 1,45 \\
\hline & & Transmissão de alarme $\left(\mathrm{s}_{2}\right)$ & 1,00 & 1,20 \\
\hline & & Extinção automática $\left(\mathrm{s}_{5}\right)$ & 1,00 & (n........ \\
\hline & & Desenfumagem $\left(s_{6}\right)$ & 1,00 & (n....... \\
\hline & \multirow{4}{*}{$\begin{array}{l}\text { Medidas de } \\
\text { construção }\end{array}$} & $\begin{array}{l}\text { Resistência da estrutura } \\
\left(\mathrm{f}_{1}\right)\end{array}$ & 1,20 & \\
\hline & & Resistência da fachada $\left(\mathrm{f}_{2}\right)$ & 1,10 & (n....... \\
\hline & & Separação entre pisos $\left(f_{3}\right)$ & 1,15 & (n....... \\
\hline & & Células corta-fogo $\left(f_{4}\right)$ & 1,20 & (n........ \\
\hline
\end{tabular}

Método de ARICA

Parâmetros comuns aos vários casos de estudo

$\mathrm{Na}$ aplicação do método de ARICA, alguns factores parciais revelaram valores idênticos em todos os casos analisados, nomeadamente $F_{I G}, F_{E S}, F_{N S L}, F_{A E}, F_{H E}$ e $F_{F}$ 0 factor parcial das instalações de gás $\left(F_{1 G}\right)$ apresenta um valor 1,0 visto que nenhuma das edificações possui qualquer instalação deste tipo.

No caso do factor parcial das equipas de segurança, $F_{E S}$, como nenhum dos edifícios possui equipas de segurança, 
ou qualquer funcionário com formação adequada de combate a incêndios, o valor é igual a 2,0.

Os factores parciais relacionados com a localização e as vias de acesso, casos $F_{A E}, F_{H E}$ e $F_{F}$ possuem igualmente valores iguais em todos os casos analisados. O factor parcial referente à acessibilidade ao edifício $\left(F_{A E}\right)$, face à localização do quarteirão em análise e às dificuldades impostas pelos arruamentos que os servem, foi considerado igual a 1,5. Quanto aos hidrantes exteriores $\left(F_{H E}\right)$, em nenhum dos casos estão a distâncias regulamentares, mas sim entre os 70 e $100 \mathrm{~m}$, considerando-se para este factor parcial o valor de 1,2. Tal como já adiantado na aplicação do Método de Gretener, não existem dados da fiabilidade da rede de abastecimento de água $\left(F_{F}\right)$, sendo adoptado nestes casos para o ARICA o valor 1,0 .

Quanto ao factor referente ao número de saídas dos locais $\left(F_{N S L}\right)$, embora os edifícios apresentem características distintas e, em alguns casos, as distâncias a percorrer até alcançar uma via de evacuação segura ou o exterior são superiores ao regulamentar, para o efectivo calculado nos vários casos o número de saídas dos locais nunca foi condicionante, obtendo-se o valor 1,0.

\section{Parâmetros específicos dos vários casos de estudo}

Nos pontos seguintes apresentam-se todos os restantes factores parciais do método, os quais são apresentados sob a forma de Quadros, sendo possível visualizar igualmente as diferenças entre as duas variantes.

- Loja de pronto-a-vestir

QUADRO X - valores dos restantes factores da loja de pronto-a-vestir.

\begin{tabular}{|c|c|c|c|c|c|c|c|c|}
\hline & & & & & & \\
\hline & \multicolumn{2}{|c|}{ Variantes } & & \multicolumn{2}{|c|}{ Variantes } & & \multicolumn{2}{|c|}{ Variantes } \\
\hline & 1 & 2 & & 1 & 2 & & 1 & 2 \\
\hline $\mathrm{F}_{\mathrm{AV}}$ & 1 & 1 & $\mathrm{~F}_{\mathrm{DVE}}$ & 1 & 1 & $F_{L}$ & 1 & 1 \\
\hline $\mathrm{F}_{\mathrm{c}}$ & 1 & 1 & $F_{E C}$ & 1 & 1 & $\mathrm{~F}_{\mathrm{NC1}}$ & 1 & 1 \\
\hline $\mathrm{F}_{\mathrm{CCF}}$ & 1,5 & 1,5 & $\mathrm{~F}_{\mathrm{EE}}$ & 1 & 1 & $\mathrm{~F}_{\mathrm{NSL}}$ & 1 & 1 \\
\hline $\mathrm{F}_{\mathrm{CF}}$ & 1 & 1 & $\mathrm{~F}_{\mathrm{ES}}$ & 2 & 1 & $\mathrm{~F}_{\mathrm{PV}}$ & 1 & 1 \\
\hline $\mathrm{F}_{\mathrm{Cl}}$ & 1 & 1 & $F_{\text {EXT }}$ & 1 & 1 & $\mathrm{~F}_{\mathrm{RIA}}$ & 1 & 1 \\
\hline $\mathrm{F}_{\mathrm{CS} / \mathrm{H}}$ & 1 & 1 & $F_{I E L}$ & 1 & 1 & $\mathrm{~F}_{\mathrm{SAE}}$ & 1 & 1 \\
\hline $\mathrm{F}_{\mathrm{DI}}$ & 1 & 0,5 & $\mathrm{~F}_{\mathrm{IVE}}$ & 1 & 1 & $\mathrm{~F}_{\mathrm{SI}}$ & 1 & 1 \\
\hline
\end{tabular}

As diferenças, entre as duas variantes resumem-se aos factores $F_{D I}$ e $F_{E S}$ (QUADRO X). O primeiro diz respeito à detecção de incêndio, que não sendo exigível regulamentarmente, na variante 1 o valor é 1,0 , pelo que ao prever-se a instalação de um SADI, o método prevê o valor de 0,5. Quanto ao factor parcial $F_{E S}$ ao prever-se uma equipa de segurança o seu valor passa a 1,0.

\section{- Tipografia}

QUADRO XI - valores dos restantes factores da tipografia.

\begin{tabular}{|c|c|c|c|c|c|c|c|c|}
\hline & \multicolumn{2}{|c|}{ Variantes } & & \multicolumn{2}{|c|}{ Variantes } & & \multicolumn{2}{|c|}{ Variantes } \\
\hline & 1 & 2 & & 1 & 2 & & 1 & 2 \\
\hline $\mathrm{F}_{A V}$ & 1 & 1 & $\mathrm{~F}_{\text {DVE }}$ & 1,49 & 1,49 & $F_{L}$ & 1,05 & 1,05 \\
\hline$F_{c}$ & 1,1 & 1,1 & $F_{E C}$ & 1,1 & 1,1 & $\mathrm{~F}_{\mathrm{NCl}}$ & 1,83 & 1,83 \\
\hline $\mathrm{F}_{\mathrm{CCF}}$ & 1,33 & 1,33 & $\mathrm{~F}_{\mathrm{EE}}$ & 2 & 1 & $\mathrm{~F}_{\mathrm{NSL}}$ & 1 & 1 \\
\hline $\mathrm{F}_{\mathrm{CF}}$ & 1 & 1 & $\mathrm{~F}_{\mathrm{ES}}$ & 2 & 1 & $\mathrm{~F}_{\mathrm{pv}}$ & 1 & 1 \\
\hline $\mathrm{F}_{\mathrm{Cl}}$ & 0,42 & 0,42 & $F_{E X T}$ & 1 & 1 & $\mathrm{~F}_{\mathrm{RA}}$ & 1,3 & 1 \\
\hline $\mathrm{F}_{\mathrm{CS} / \mathrm{H}}$ & 1,5 & 1,5 & $F_{I E L}$ & 1 & 1 & $\mathrm{~F}_{\mathrm{SAE}}$ & 2 & 1 \\
\hline $\mathrm{F}_{\mathrm{DI}}$ & 1 & 1 & $\mathrm{~F}_{\text {IVE }}$ & 1 & 1 & $\mathrm{~F}_{\mathrm{SI}}$ & 2 & 1 \\
\hline
\end{tabular}

A segunda variante apresenta cinco factores parciais distintos da situação existente (QUADRO XI). A previsão de equipas de segurança e a realização de exercícios de evacuação garante aos factores $F_{E E}$ e $F_{E S}$ o valor 1,0. Os restantes factores dizem respeito à montagem de sinalização e iluminação de emergência $\left(F_{S l}\right)$, instalação uma rede de incêndio armada $\left(F_{\text {RIA }}\right)$ e dum sistema automático de extinção a água $\left(\mathrm{F}_{\mathrm{SAE}}\right)$. Estes 3 factores passam a ter o valor 1,0 , porque não existem os meios no edifício actualmente.

\section{- Ourivesaria}

QUADRO XII - valores dos restantes factores da ourivesaria.

\begin{tabular}{|c|c|c|c|c|c|c|c|c|}
\hline & \multicolumn{2}{|c|}{ Variantes } & & \multicolumn{2}{|c|}{ Variantes } & & \multicolumn{2}{|c|}{ Variantes } \\
\hline & 1 & 2 & & 1 & 2 & & 1 & 2 \\
\hline $\mathrm{F}_{\mathrm{AV}}$ & 1 & 1 & $\mathrm{~F}_{\mathrm{DVE}}$ & 1 & 1 & $\mathrm{~F}_{\mathrm{L}}$ & 1 & 1 \\
\hline $\mathrm{F}_{\mathrm{c}}$ & 1,1 & 1 & $\mathrm{~F}_{\mathrm{EC}}$ & 1,1 & 1,1 & $\mathrm{~F}_{\mathrm{NC1}}$ & 1 & 1 \\
\hline $\mathrm{F}_{\mathrm{CCF}}$ & 1,5 & 1,5 & $\mathrm{~F}_{\mathrm{EE}}$ & 1 & 0,5 & $\mathrm{~F}_{\mathrm{NSL}}$ & 1 & 1 \\
\hline $\mathrm{F}_{\mathrm{CF}}$ & 1 & 1 & $\mathrm{~F}_{E S}$ & 2 & 1 & $\mathrm{~F}_{\mathrm{PV}}$ & 1 & 1 \\
\hline $\mathrm{F}_{\mathrm{Cl}}$ & 1,19 & 1,19 & $\mathrm{~F}_{\mathrm{EXT}}$ & 1,2 & 1 & $\mathrm{~F}_{\mathrm{RIA}}$ & 1 & 0,8 \\
\hline $\mathrm{F}_{\mathrm{CS} / \mathrm{H}}$ & 1 & 1 & $\mathrm{~F}_{\mathrm{IEL}}$ & 1,5 & 1 & $F_{S A E}$ & 1 & 1 \\
\hline $\mathrm{F}_{\mathrm{DL}}$ & 1,2 & 0,5 & $\mathrm{~F}_{\mathrm{INE}}$ & 1 & 1 & $\mathrm{~F}_{\mathrm{S} \backslash}$ & 2 & 1 \\
\hline
\end{tabular}

Das alterações evidenciadas, prevê-se a instalação de extintores portáteis $\left(\mathrm{F}_{\mathrm{EXT}}\right)$, que na situação existente são inexistentes, e a adequação das instalações eléctricas $\left(F_{\text {IEL }}\right)$ que se encontram em mau estado de conservação, como exigências regulamentares (QUADRO xII). Os factores $F_{D D}$, $F_{E E}$ e $F_{R I A}$, obtiveram valores inferiores a 1 porque apesar de serem previstos o regulamento não o exige. 0 factor de correcção $\left(F_{c}\right)$ é alterado, porque passamos duma situação em que não estão garantidas todas as exigências regulamentares para uma situação regulamentar.

- Edifício de escritórios

QUADRO XIII - valores dos restantes factores do edifício de escritórios.

\begin{tabular}{|c|c|c|c|c|c|c|c|c|}
\hline & \multicolumn{2}{|c|}{ Variantes } & & \multicolumn{2}{|c|}{ Variantes } & & \multicolumn{2}{|c|}{ Variantes } \\
\hline & 1 & 2 & & 1 & 2 & & 1 & 2 \\
\hline $\mathrm{F}_{\mathrm{AV}}$ & 1,05 & 1,05 & $\mathrm{~F}_{\mathrm{DVE}}$ & 2 & 2 & $F_{L}$ & 1 & 1 \\
\hline$F_{c}$ & 1,2 & 1,2 & $\mathrm{~F}_{\mathrm{EC}}$ & 1 & 1 & $\mathrm{~F}_{\mathrm{NCl}}$ & 1 & 1 \\
\hline $\mathrm{F}_{\mathrm{CCF}}$ & 1 & 1 & $\mathrm{~F}_{\mathrm{EE}}$ & 2 & 1 & $\mathrm{~F}_{\text {NSL }}$ & 1 & 1 \\
\hline $\mathrm{F}_{\mathrm{CF}}$ & 2 & 2 & $\mathrm{~F}_{\mathrm{ES}}$ & 2 & 1 & $\mathrm{~F}_{\mathrm{PV}}$ & 1,67 & 1,67 \\
\hline $\mathrm{F}_{\mathrm{Cl}}$ & 1,19 & 1,19 & $F_{E X T}$ & 1,2 & 1 & $\mathrm{~F}_{\mathrm{RIA}}$ & 1,3 & 1 \\
\hline $\mathrm{F}_{\mathrm{CS} / \mathrm{H}}$ & 1 & 1 & $F_{I E L}$ & 1 & 1 & $\mathrm{~F}_{S A E}$ & 1 & 1 \\
\hline$F_{D 1}$ & 2 & 1 & $F_{\text {IVE }}$ & 1,05 & 1,05 & $F_{S \downarrow}$ & 2 & 1 \\
\hline
\end{tabular}


Este edifício, apesar de encerrar inúmeras situações não regulamentares, não permite uma fácil implementação de medidas correctivas de segurança contra incêndio. Os factores alterados resumem-se à previsão de um SADI $\left(F_{D I}\right)$, realização de exercícios de evacuação $\left(F_{E E}\right)$, criar equipa de segurança $\left(F_{E S}\right)$, instalar extintores portáteis $\left(F_{E X T}\right)$, montagem de rede de incêndios armada $\left(F_{R I A}\right)$ e colocação de sinalização e iluminação de emergência $\left(\mathrm{F}_{\mathrm{SI}}\right)$ (QUADRO $\left.\mathrm{XIII}\right)$. Todas as restantes medidas regulamentares exigíveis são inexequíveis devido às condicionantes arquitectónicas do edifício.

\section{Análise dos valores de risco de incêndio obtidos}

\section{Valores de risco de incêndio}

Os valores de riso de incêndio obtidos pelos métodos de Gretener e de ARICA constam da QUADRO xIV:

QUADRO XIV - factores de risco incêndio obtidos.

\begin{tabular}{|l|l|l|l|l|}
\cline { 2 - 5 } \multicolumn{1}{c|}{} & \multicolumn{2}{l|}{ Variante 1} & \multicolumn{2}{l|}{ Variante 2} \\
\cline { 2 - 5 } \multicolumn{1}{c|}{} & Gretener & ARICA & Gretener & ARICA \\
\hline Loja de pronto-a-vestir & 4,29 & 1,91 & 1,39 & 1,04 \\
\hline Tipografia & 0,50 & 2,44 & 1,13 & 1,05 \\
\hline Ourivesaria & 0,74 & 3,30 & 1,80 & 1,00 \\
\hline Edifício de escritórios & 1,30 & 4,65 & 3,92 & 1,70 \\
\hline
\end{tabular}

\section{Comentário dos resultados obtidos}

Os resultados obtidos para cada um dos casos analisados chegam a ser tão distintos quanto os dois métodos utilizados. O caso mais notório das discrepâncias nos resultados obtidos pelos dois métodos é claramente o edifício de escritórios. No método de Gretener a situação actual é considerada satisfatória, obtendo-se um valor superior ao mínimo previsto para garantir um risco de incêndio aceitável. Na aplicação do método de ARICA prevendo-se todas as medidas consideradas exequíveis, o valor não se aproximou do mínimo para se considerar o risco de incêndio aceitável.

Através da aplicação do Método de Gretener, na tipografia e na ourivesaria, a segurança contra incêndio era insuficiente, enquanto os restantes dois casos o valor era suficiente. Sem surpresas, pelo Método ARICA todos os casos estudados apresentam necessidade de melhorias na segurança contra incêndio do edifício. Embora os resultados obtidos no ARICA fossem os esperados, visto tratar-se de edificações que não cumprem as prescrições regulamentares, o mesmo não se verificou com os resultados obtidos pelo Gretener. O caso mais paradigmático foi o do edifício de escritórios, pois apesar de ser um edifício de seis pisos, sem qualquer medida passiva ou activa de protecção, a aplicação do Gretener resultou na obtenção dum risco de incêndio aceitável.

\section{Conclusões}

O método de Gretener, apesar das suas potencialidades, tem limitações que não podem ser ignoradas e que são mais evidentes quando aplicado aos centros urbanos antigos, pois foi pensado para edifícios industriais. As suas limitações, quando aplicado aos edifícios situados nestes centros, decorrem da ausência de diversos factores com influência decisiva no risco. Nota-se a ausência dum factor que faça intervir o estado de conservação do edifício, o estado das instalações, a possibilidade de propagação do incêndio entre os edifícios, etc.

No que concerne ao método ARICA a sua principal insuficiência reside na não consideração da possibilidade de propagação do incêndio entre edifícios vizinhos e nos valores adoptados para alguns dos factores.

A aplicação do método de Gretener à tipografia e a ourivesaria, levou a que tivesse que ser instalado nestes estabelecimentos, extintores portáteis e sistemas de detecção como medida para alcançar a desejada segurança contra incêndio. Na tipografia foi ainda necessário considerar novas medidas de construção.

No método de ARICA, nos casos estudados, exceptuando a loja pronto-a-vestir, foi necessário prever medidas adicionais de segurança contra incêndio, para além das existentes. Nestas destacam-se a formação dos funcionários em combate a incêndios, a realização de exercícios de evacuação e a colocação duma rede de incêndios do tipo carretel. No edifício de escritórios e na ourivesaria foram ainda instalados extintores portáteis, enquanto na tipografia foi prevista a instalação dum sistema automático de extinção de incêndios por água.

A finalizar refere-se que os resultados obtidos, a partir dos métodos de Gretener e de ARICA, permitiram identificar diferenças entre eles. $O$ primeiro é menos abrangente nas várias valências da segurança contra incêndio, enquanto o segundo considera na sua formulação praticamente todos os aspectos que influenciam o risco de incêndio.

\section{Referências bibliográficas:}

Lemos, A. M. T. e Neves, I. C. (1987) - “Avaliação do Risco de Incêndio. Método de Cálculo”. Universidade Técnica de Lisboa. Lisboa, Portugal.

Fernandes, A. M. S. (2006) - "Segurança ao Incêndio em Centros Urbanos Antigos”. Dissertação para Mestrado, Departamento de Engenharia Civil da Universidade de Coimbra. Coimbra, Portugal;

Figueira, R. A. F. (2008) - "Avaliação do Risco de Incêndio em Centros Urbanos Antigos”. Dissertação para Mestrado, Departamento de Engenharia Civil da Universidade de Coimbra. Coimbra, Portugal. 